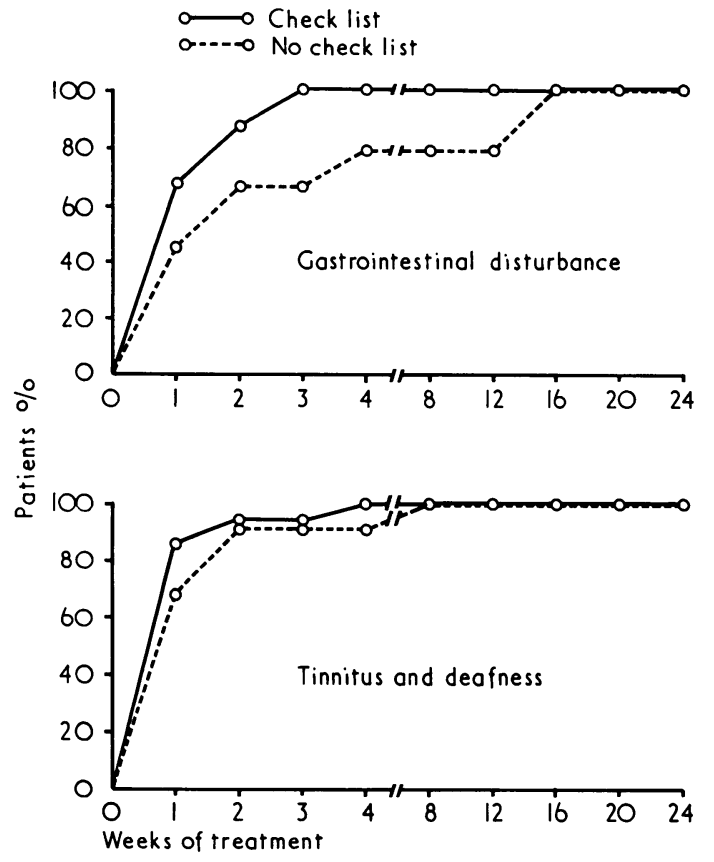

Cumulative number of patients (expressed as percentage of total number complaining) with gastrointestinal or auditory side effects due to aspirin therapy.

\section{Discussion}

The results of this study confirm the finding of Greenblatt (1964) that side effects are more likely to be elicited if a check list is used. They also suggest that relevant side effects are more likely to be detected if a check list is not used. The check list is most likely to interfere with the collection of symptoms which occur frequently even in the absence of drug therapy. This is illustrated by the incidence of gastrointestinal disturbance in the study. Many people, and especially patients with rheumatoid arthritis, suffer minor gastrointestinal irregularities and if prompted by a check list will volunteer these as potential drug induced side effects.

The evidence also suggests that the totally unexpected side effect of a drug is more likely to be detected when a check list is not used. If this side effect is included in the check list its apparent incidence will be reduced by reports of its occurrence in the control group; if it is not included in the check list it is less likely to be reported.

It is well known that side effects occur on placebo therapy just as symptoms occur in normal people. This phenomenon is a nuisance in the detection of side effects of drugs. Since check lists increase the incidence of irrelevant complaints they should not be used.

\section{References}

Greenblatt, M. (1964). Clinical Pharmacology and Therapeutics, 5, 864. Huskisson, E. C., et al. (1974). British Medical fournal, 1, 176.

\title{
Propranolol in the Treatment of Migraine
}

\author{
TOR-ERIK WIDER $\varnothing \mathrm{E}, \quad$ TOR VIGANDER
}

British Medical fournal, 1974, 2, 699-701

\section{Summary}

Beta-blocking drugs that prevent cranial vasodilatation are potentially valuable in the prophylaxis of migraine. Forty-nine patients with either classic or common migraine were treated with propranolol $160 \mathrm{mg} /$ day for an average of six months. The first 30 of the patients to respond well to this treatment then participated in a double-blind cross-over trial with a placebo and propranolol. The mean frequency of headache attacks was significantly reduced by propranolol. None of the patients expressed a preference for placebo. Propranolol seems to be an effective prophylactic for common and classic migraine but the antimigraine properties of the various beta-blocking agents probably differ.

\section{Introduction}

The intensity of migraine is closely related to the amount of dilatation of the extracranial arteries (Wolff, 1963) and the vessels of the bulbar conjunctiva (Piovella, 1972). Furthermore, \footnotetext{
Nephrological Department, Regional Hospital in Trondheim,
Norway

TOR-ERIK WIDER $\phi E$, M.D.

Medical Department, Orkdal Hospital, Norway

TOR VIGANDER, M.D.
}

migraine is alleviated by agents which produce cranial vasoconstriction. Falck et al. (1968) showed that the vessels of the pia mater contain both alpha- and beta-adrenergic receptors and that beta-blocking agents may affect the cerebral blood flow. That beta-blocking agents are potentially of value in the treatment of migraine headache has been proved empirically (Rabkin, 1966; Bekes et al., 1968; Wykes, 1968; Lund-Larsen, 1969; Wideroe, 1969) and by controlled trials (Weber and Reinmuth, 1971; Malvea et al., 1973). Ekbom and Lundberg (1972) and Sjaastad and Stensrud (1972), however, found that pindolol had no significant antimigraine effect.

The aim of this study was to investigate the value of propranolol in preventing attacks of migraine.

\section{Patients and Methods}

We asked doctors in the region to refer to us all patients suffering from migraine who might benefit from prophylactic treatment. Altogether we examined about 100 patients. Forty-nine (44 women and five men) were diagnosed as having either "classic" or "common" migraine (Ad Hoc Committee, 1962). Their ages ranged from 18 to 55 years with an average of 40 years. All except four patients had two or more attacks a month. They were all treated as outpatients. All had been taking antimigraine drugs, in most cases with some benefit.

Each of the 49 patients was entered in a pilot study in which for a period averaging six months (range 2-24 months) they were given propranolol $40 \mathrm{mg}$ by mouth four times daily. Attacks were treated by the usual antimigraine drugs. The patients kept a record of the frequency, intensity, and duration of their 
attacks, and any changes in premonitory symptoms, quality of the attack, degree of invalidity, and consumption of analgesic and antimigraine drugs were noted. The patients were seen every one to two months, when the protocol was discussed and supplemented if necessary and the heart rate and blood pressure were recorded. The result of treatment was rated as follows: (1) excellent-a reduction in attack rate of more than $50 \%$; (2) moderate-a reduction in attack rate of less than $50 \%$; (3) no effect; (4) an increase in attack rate.

The first 30 patients (26 women and four men) in whom the result of treatment was rated as excellent were chosen for a double-blind cross-over study. Their age range was 18-55 years (average 38 years). Six had classic and 24 had common migraine. They had been taking propranolol for an average period of 5.6 months (range 2-11 months).

In the double-blind cross-over study the 30 patients were given either propranolol or a placebo in a randomized way for two three-month periods. Each patient was seen monthly by the same physician who treated him or her in the pilot study and the same examination was carried out except that heart rate and blood pressure were not measured. To avoid introducing unnecessary bias the patients were told that different treatments were to be compared and that their effect might vary.

The difference in frequency of migraine attacks per month for the two periods was calculated statistically by using the attack rate as "Poisson-intensity."

\section{Results}

The results of treatment during the pilot study were excellent in $41(84 \%)$ patients, moderate in six $(12 \%)$, and of no effect in two $(4 \%)$. No patient had an increase in attack rate. Most described their attacks as less severe and of shorter duration. The consumption of drugs other than propranolol was much reduced and in some cases abandoned. The 30 patients who went on to take part in the controlled trial had had an average of three attacks a month before the treatment started. This was reduced to an average of 0.5 attacks a month during the pilot study (table). In the patients with classic migraine the reduction was from 2.7 to 0.6 attacks and in those with common migraine from 3.1 to 0.4 .
Four of the 30 patients chosen for the controlled trial had later to be excluded from it for reasons that were not relevant to the study. Among the 26 remaining patients the average attack rate was 0.4 while on propranolol compared with 1.7 while on placebo. The corresponding rates among the patients with classic and those with common migraine were 0.9 and 2.1 and 0.2 and 1.5 respectively (see table). Statistically the attack rate was at least twice as high in the common migraine group with placebo treatment and even higher in the classic migraine group at a significance level of $P=0.005$. Twenty-one ( $81 \%$ ) patients preferred propranolol while five $(19 \%)$ patients showed no preference. Thus there were none who preferred placebo.

None of the patients had to discontinue treatment because of side effects. Five in the pilot study initially complained of slight insomnia. Most also had a slightly reduced heart rate and slightly lowered blood pressure. There were no cardiopulmonary side effects.

Two other patients (not included in the trial) with severe migraine and obstructive bronchopulmonary disease were given small doses of propranolol $(40-80 \mathrm{mg} /$ day) under strict supervision. The effect on their migraine was excellent but their respiratory function worsened. Practolol was therefore substituted for propranolol. Respiratory function then improved but the migraine attacks became so disabling that both patients insisted on returning to propranolol. This was given in small doses and the effect continued to be excellent.

\section{Discussion}

The results of these trials show that propranolol is highly effective in the prophylactic treatment of both classic and common migraine. The reduction in the attack rate could be explained by the action of propranolol on the natural course of the disease, by a carry-over effect from the preceding propranolol treatment, or by a doctor-patient interaction.

We think that the treatment with propranolol during the pilot study changed the "character" of the migraine. A doctorpatient interaction or placebo effect seems the most unlikely. Friedman et al. (1957) noted improvement in half of 1,644 migrainous patients treated prophylactically with placebo. But

Effects of Propranolol and Placebo on Average Monthly Number of Headache Attacks

\begin{tabular}{|c|c|c|c|c|c|c|c|c|c|}
\hline \multirow{3}{*}{ Case No. } & \multirow{3}{*}{ Sex } & \multirow{3}{*}{$\underset{\text { Type }}{\text { Migraine }}$} & \multirow{3}{*}{$\begin{array}{c}\text { No. of } \\
\text { Attacks } \\
\text { Before } \\
\text { Treatment }\end{array}$} & \multicolumn{2}{|c|}{ Pilot Study } & \multicolumn{4}{|c|}{ Controlled Study* } \\
\hline & & & & \multirow{2}{*}{$\begin{array}{l}\text { No. of } \\
\text { Attacks }\end{array}$} & \multirow{2}{*}{$\begin{array}{l}\text { Duration } \\
\text { (Months) }\end{array}$} & \multirow{2}{*}{$\begin{array}{c}\text { Initial } \\
\text { Medication }\end{array}$} & \multicolumn{2}{|c|}{ No. of Attacks } & \multirow{2}{*}{$\begin{array}{c}\text { Propranolol } \\
\text { Preference }\end{array}$} \\
\hline & & & & & & & Propranolol & Placebo & \\
\hline $\begin{array}{l}1 \\
2 \\
3 \\
4 \\
5 \\
6 \\
7 \\
8 \\
9 \\
10 \\
11 \\
12 \\
13 \\
14 \\
15 \\
16 \\
17 \\
18 \\
19 \\
20 \\
21 \\
22 \\
23 \\
24 \\
25 \\
26 \\
27 \\
28 \\
29 \\
30\end{array}$ & $\begin{array}{l}\text { F. } \\
\text { M. } \\
\text { F. } \\
\text { F. } \\
\text { M. } \\
\text { F. } \\
\text { F. } \\
\text { F. } \\
\text { F. } \\
\text { F. } \\
\text { F. } \\
\text { F. } \\
\text { F. } \\
\text { F. } \\
\text { F. } \\
\text { F. } \\
\text { F. } \\
\text { F. } \\
\text { F. } \\
\text { F. } \\
\text { M. } \\
\text { F. } \\
\text { F. } \\
\text { F. } \\
\text { F. } \\
\text { F. } \\
\text { F. } \\
\text { F. }\end{array}$ & 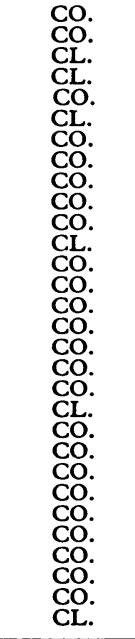 & $\begin{array}{l}4 \\
2 \\
2 \cdot 5 \\
4 \\
6 \\
2 \\
1 \\
3 \cdot 5 \\
4 \\
1 \cdot 5 \\
2 \cdot 5 \\
4 \\
2 \\
3 \cdot 5 \\
1 \\
4 \\
4 \\
2 \\
4 \\
1 \cdot 5 \\
3 \\
4 \\
2 \\
3 \\
3 \\
4 \\
3 \\
4 \\
4 \\
2\end{array}$ & $\begin{array}{l}0 \cdot 1 \\
0 \cdot 6 \\
0 \cdot 6 \\
0 \cdot 9 \\
1 \cdot 1 \\
0 \cdot 3 \\
0 \cdot 3 \\
0 \cdot 2 \\
0 \cdot 1 \\
0 \cdot 5 \\
0 \cdot 3 \\
0 \cdot 6 \\
0 \\
1 \cdot 4 \\
0 \\
0 \\
1 \cdot 1 \\
0 \cdot 3 \\
0 \cdot 6 \\
0 \cdot 4 \\
0 \\
0.5 \\
1 \\
1 \cdot 4 \\
1 \\
0 \\
0 \cdot 3 \\
0 \\
1 \cdot 5 \\
0.5\end{array}$ & $\begin{array}{r}10 \\
9 \\
8 \\
10 \\
8 \\
8 \\
4 \\
9 \\
11 \\
2 \\
3 \\
3 \cdot 5 \\
2 \\
3 \cdot 5 \\
9 \\
6 \\
10 \\
9 \cdot 5 \\
9 \\
5 \cdot 5 \\
2 \\
2 \\
2 \\
8 \\
3 \\
3 \\
3 \\
2 \\
2 \\
2\end{array}$ & $\begin{array}{l}\text { PR. } \\
\text { PL. } \\
\text { PL. } \\
\text { PR. } \\
\text { PR. } \\
\text { PL. } \\
\text { PR. } \\
\text { PL. } \\
\text { PL. } \\
\text { PR. } \\
\text { PR. } \\
\text { PL. } \\
\text { PL. } \\
\text { PR. } \\
\text { PL. } \\
\text { PR. } \\
\text { PR. } \\
\text { PL. } \\
\text { PR. } \\
\text { PL. } \\
\text { Discontinued } \\
\text { PR. } \\
\text { Discontinued } \\
\text { PR. } \\
\text { Discontinued } \\
\text { PL. } \\
\text { PL. } \\
\text { PL. } \\
\text { Discontinued } \\
\text { PL. }\end{array}$ & $\begin{array}{l}0 \\
0 \cdot 3 \\
1 \\
1 \\
1 \\
1 \\
0 \\
0 \\
0 \\
0 \cdot 3 \\
1 \\
1 \cdot 3 \\
0 \cdot 3 \\
0 \\
0 \\
0 \cdot 7 \\
0 \\
0 \\
0 \\
0 \cdot 3 \\
0 \\
1 \cdot 3 \\
0 \\
0 \\
0 \\
0 \cdot 7\end{array}$ & $\begin{array}{l}0 \\
0.7 \\
3 \\
2.3 \\
3 \\
1 \\
0 \cdot 7 \\
0 \\
0.3 \\
1.3 \\
5 \cdot 3 \\
2 \cdot 3 \\
1.7 \\
0 \cdot 7 \\
0 \\
0.7 \\
0 \cdot 3 \\
0 \cdot 7 \\
1.3 \\
1.3 \\
3 \\
3 \\
2.7 \\
2 \\
4 \cdot 3 \\
3\end{array}$ & 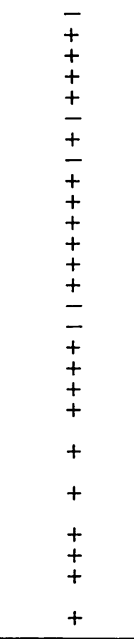 \\
\hline & Mean values & $\left\{\begin{array}{l}\text { Total } \\
\text { Common } \\
\text { Classic }\end{array}\right.$ & $\begin{array}{l}3 \\
3 \cdot 1 \\
2 \cdot 7\end{array}$ & $\begin{array}{l}0.5 \\
0.4 \\
0.6\end{array}$ & $6 \cdot 1$ & & $\begin{array}{l}0.4 \\
0.2 \\
0.9\end{array}$ & $\begin{array}{l}1.7 \\
1.5 \\
2.1\end{array}$ & \\
\hline
\end{tabular}


in the present study as much as $81 \%$ of the patients preferred propranolol and none preferred the placebo. That does not exclude any placebo effect but it does show that propranolol has antimigraine properties. Several of the patients who improved on propranolol complained that their migraine attacks increased in frequency, intensity, and duration during the start of the placebo period. Therefore there is little reason to suspect a carry-over effect of propranolol.

The optimal antimigraine dose of propranolol is not known. We, like Lund-Larsen (1969), found doses as low as $40-60 \mathrm{mg}$ daily effective. Doses of more than $160 \mathrm{mg}$ daily were not given. Propranolol is effective in migraine probably because it prevents vasodilatation of the cerebral arteries. Seemingly the various beta-blockers act differently in migraine. The pharmacological properties of the different beta-blocking drugs are known to differ. Propranolol has no intrinsic sympathomimetic activity (Johnson, 1967; Barret, 1971) and its action on the peripheral vascular beta-receptors is said to be greater than that of other beta-blocking agents. Both pindolol and practolol are cardioselective (Barret, 1971; Beumer and Hardouck, 1971; Gunther and Kamburoff, 1971; McNeill, 1971) and have little effect at the peripheral vascular beta-receptors.

The placebo and propranolol (Inderal) were kindly supplied by Imperial Chemical Industries Ltd. We thank the company for their help in randomizing the substances. We also thank Cand. Real. Harald Horten, department of statistics, University of Trondheim $-\mathrm{NTH}$, for the statistical evaluation.

\section{References}

Ad Hoc Committee. (1962). Fournal of the American Medical Association, $179,717$.

Barret, A. M. (1971). Postgraduate Medical fournal, Supplement, 47, 7. Bekes, M., et al. (1968). Lancet, 2, 980.

Beumer, H. M. and Hardonk, H. J. (1971). Medizinische Klinik, 66, 1804

Beumer, H. M., and Hardon, P. O. (1972). Headache, 12, 15.

Ekbom, K., and Lundberg, P. O. (1972). Headache, 12, 15. Faboratory and Clinical Investigation, Supplement, 102, 96.

Friedman, A. P., and Morritt, H. (1957). fournal of the American Medical Association, 163, 1111

Günthner, W., and Kamburoff, P. L. (1971). Therapiewoche, 21, 4060 Johnson, G. (1967). Acta Pharmacologica et Toxicologica, 25, Suppl. 2, 63. Lund-Larsen, P. C. (1969). Tidsskrift for den Norske Laegeforening, 89, 1121. Malvea, B. P., Owon, N., and Graham, J. R. (1973). Headache, 12, 163. McNeill, R. S. (1971). Postgraduate Medical fournal, Supplement, 47, 14.

Piovella, C. (1972). Research and Clinical Studies in Headache, 3, 277.

Rabkin, R et al (1966). American fournal of Cardiology, 18, 370.

Sjaastad, O., and Stensrud, P. (1972). Acta Neurologica Scandinavica, 48, 124

Weber, R. B., and Reinmuth, O. M. (1971). Neurology, 21, 404

Weber, R. B., and Reinmuth,

Wolff, H. G. (1963). Headache and other head pain, 2nd. ed. New York, Oxford University Press.

Oxford University Press.
Wykes, P. (1968). Practitioner, 200, 702.

\title{
Response to Influenza Vaccine by Renal Transplant Patients
}

\author{
R. N. P. CARROLL, \\ S. D. MARSH, \\ E. P. N. O'DONOGHUE, \\ D. C. BREEZE, \\ R. SHACKMAN
}

British Medical fournal, 1974, 2, 701-703

\section{Summary}

Twenty-five renal transplant patients and 17 controls were vaccinated with influenza vaccine. Antibody titres were estimated before and one, three, and 12 months after vaccination. On the basis of antibody titre measurements the transplant group showed a similar qualitative and quantitative response to that of the controls. No rejection episodes occurred among the transplant patients as a result of vaccination and nobody in the trial developed influenza. We conclude that it is safe to vaccinate transplant patients with an inactivated influenza vaccine and that protection (haemagglutination-inhibiting antibody) can be induced.

\section{Introduction}

In 1969 we vaccinated renal transplant patients, haemodialysis

Urology Unit, Department of Surgery, Hammersmith Hospital and Royal Postgraduate Medical School, Ducane Road, London W12 OHS

R. N. P. CARROLL, F.R.C.s., Urology Registrar (Now Consultant Urologist, Manchester Royal Infirmary)

E. P. N. O'DONOGHEU, F.R.C.S., Urology Registrar

R. SHACKMAN, F.R.C.S., Professor of Urology

Clinical Research Unit, Glaxo Laboratories Ltd., Greenford Middlesex

S. D. MARSH, M.SC., B.PHARM., Research Assistant (Now Clinical Trial Officer, Allen and Hanbury's Research)

Evans Biologicals Ltd., Speke, Liverpool

D. C. BREEZE, PH.D., M.I.BIOL., Technical Director patients, and controls with a half-strength vaccine against Hong Kong influenza. Because some of the transplant patients showed a protective rise in antibody response we subsequently vaccinated a further group of transplant patients with a stronger vaccine in the winter of 1970-1. We report here the results of the stronger vaccine.

\section{Subjects and Methods}

Control Group.- - Seventeen members of the medical and nursing staff volunteered as a control group for vaccination.

Transplant Group.-Twenty-five transplant patients who had received their grafts six months-four years earlier volunteered for vaccination. They were receiving maintenance doses of prednisone $15 \mathrm{mg}$ and azathioprine $100-200 \mathrm{mg}$ daily depending on body weight and their susceptibility to leucopenia.

Vaccine.-The vaccine consisted of 400 IU of A/Hong Kong/ $1 / 68\left(\mathrm{H}_{3} \mathrm{~N}_{2}\right)$ and $200 \mathrm{IU}$ of $\mathrm{B} /$ England/5/66 (Admune, manufactured for B.D.H. Pharmaceuticals, ${ }^{*}$ London, by Evans Medical Limited, Speke, Liverpool). The vaccine was manufactured to the then current British Pharmocopoeia and Therapeutic Substances Act regulations.

Sera.-Before vaccination and at one, three, and 12 months after vaccination blood was withdrawn for antibody titre and serum creatinine estimations. Serum was removed from coagulated whole blood after centrifugation and stored at $-30^{\circ} \mathrm{C}$. Each serum was treated with cholera flitrate to remove nonspecific inhibitors. Serum $(0.2 \mathrm{ml})$ and cholera filtrate $(1 \mathrm{ml})$ were incubated for 18 hours at $37^{\circ} \mathrm{C}$ in a water bath. Subsequently, each serum-cholera filtrate mixture was inactivated at $56^{\circ} \mathrm{C}$ for one hour in a water bath. The treated serum was taken as a 1/6 dilution in calculating the results.

Haemagglutination Inhibition Test.-Serial dilutions of each *Now known as Duncan Flockhart and Co. Ltd. 